\title{
Crianças, ética do cuidado e direitos: a propósito do Estatuto da Criança e do Adolescente
}

\section{Resumo}

\author{
Sonia Kramer $^{1}$ \\ ORCID: 0000-0002-5776-2677 \\ Maria Fernanda Rezende Nunes ${ }^{2}$ \\ ORCID: 0000-0003-3696-9369 \\ Alexandra Pena ${ }^{1}$ \\ ORCID: 0000-0003-3363-6059
}

0 texto analisa as relações entre cuidado e direitos das crianças, a partir dos resultados de um estudo feito por um grupo de pesquisa interinstitucional, da qual participaram alunos e professores de duas universidades. As contribuições apresentadas buscam problematizar, inquietar e, se possível, afetar modos de pensar e de agir em instituições comprometidas com as conquistas do Estatuto da Criança e do Adolescente. A investigação voltou-se para práticas positivas de cuidado em seis instituições públicas municipais (duas creches; duas pré-escolas; duas escolas de Ensino Fundamental) que atendem da Educação Infantil ao Ensino Fundamental. 0 referencial teórico baseia-se em Martin Buber e os conceitos de vínculo, confiança e presença; cuidar e ser cuidado. As histórias de vida foram a opção metodológica. Trata-se de abordagem com tradição no campo da pesquisa sociológica e nas pesquisas em educação voltadas para a produção de um conhecimento que não dicotomiza vida pessoal e profissional, sujeito e objeto, cotidiano e história. 0 texto procura dar visibilidade ao que se ouviu, a partir de entrevistas e oficinas, acerca do cuidado de professores, familiares e crianças que frequentavam as seis instituições. 0 cuidado, de si, do outro, de todos - em especial das crianças -, é algo relacionado à sobrevivência. Eis um dos aspectos que emerge da pesquisa apresentada. A ética do cuidado é exigência para que a esfera humana, a humanidade, não seja destruída. Ela significa presença do adulto, reciprocidade, vínculo, encontro.

\section{Palavras-chave}

Educação infantil - Direitos das crianças - Cuidado - Estatuto da Criança e do Adolescente.

1- Pontifícia Universidade Católica do Rio de Janeiro, Rio de Janeiro, RJ, Brasil. Contatos: sokramer@puc-rio.br; alexandrapena@puc-rio.br. 2- Universidade Federal do Estado do Rio de Janeiro, Rio de Janeiro, RJ, Brasil. Contato: nunes.mariafernandarezende@gmail.com. 


\section{Children, ethics in caregiving and rights: the reason for the Statute of Child and Adolescent*}

\section{Abstract}

The text analyzes the association between caregiving and the right of children based on results recorded in a study carried out by an inter-institutional research, which comprised students and professors from two universities. The herein presented contributions aim at problematizing, annoying and, somehow, affecting the ways of thinking and acting in institutions committed to conquests achieved through the Statute of Child and Adolescent. The investigation headed towards positive caregiving practices in six municipal public institutions (two daycare centers; two pre-schools; two elementary schools) that provide from Child Education to Elementary School. The theoretical reference is based on Martin Buber, as well as on bond, trust and presence concepts; caregiving and to be taken care of. Life stories were the methodological option; this approach is traditional in sociological research fields and in education research focused on the production of knowledge that does not set the dichotomy personal vs. professional life, subject vs. object; daily life vs history. The aim of the text is to give some visibility to what was heard in interviews and workshops about the care provided by teachers and family members to children attending to the six assessed institutions. Taking care of oneself, and of others, or even of all others - mainly of children -, is a factor related to survival; it is one of the aspects rising from the herein presented research. Ethics in caregiving is mandatory so the human sphere, mankind, does not face the risk of being annihilated. Such ethics means having the presence of an adult, reciprocity, bond and encounter.

\section{Keywords}

Child education - Right of the children - Care - Statute of Child and Adolescent.

\section{Introdução: o cuidado como direito}

Este texto foi escrito em um contexto complexo. Dizê-lo difícil seria pouco, por se tratar de uma profunda crise econômica de grandes proporções mundiais, combinada à instabilidade política vivida no Brasil e à desigualdade social que marca a história da nossa sociedade, no âmago da pandemia do vírus Covid 19, que vem afetando gravemente a saúde das populações em todo mundo, ao longo do ano de 2020.

Comparável à gripe espanhola, cerca de cem anos depois, essa situação crítica, multifacetada, atinge e altera o cotidiano, as rotinas, as ações e as relações. Como continuar, então, a trabalhar? Como cuidar dos mais vulneráveis, no caso, das crianças que estão em casa ou - desprovidas das mínimas condições dignas de vida - na rua?

*English version by Deyse Assis de Miranda. 
$\mathrm{Ou}$, ainda, daquelas institucionalizadas em abrigos? Como prover acolhimento, comida, proteção, assistência, saúde? Como atuar com a responsabilidade de adultos, professores, pesquisadores, gestores de instituições públicas ou privadas? Como implementar políticas públicas de modo a garantir que não seja aprofundado o risco em que já viviam?

Ora, se o contexto e a necessidade de proteção de cada qual são motivo e motivação para favorecer a saúde de todos/as, enquanto não se dispõem de medicação e vacina comprovadas cientificamente para tratar ou impedir a doença, o momento em que nos encontramos convoca-nos mais uma vez à resistência. Ou, melhor dizendo, somos convocados a manter-nos resistentes, seja contando a história do que se conseguiu, rememorando lutas e conquistas; seja apontando o que ficou de fora, os desafios, limites, as perdas e dificuldades a enfrentar.

Trazer o Estatuto da Criança e do Adolescente (ECA) com esse foco é compreender que "A história é objeto de uma construção cujo lugar não é o tempo homogêneo e vazio, mas um tempo saturado de 'agoras”' (BENJAMIN, 1987, p. 229). Com um salto de tigre, é preciso se voltar à origem, contra a barbárie em que historicamente vêm sendo colocadas parcelas importantes das populações, em geral, e infantis, em particular. 0 Estatuto resultou de muito trabalho, aliando intensa militância política, investigação acadêmica, reflexão teórica e atuação prática de profissionais de diversas áreas, campos do conhecimento e da cultura e reverteu uma trajetória de documentos, políticas e ações que não contribuíam para a educação e o cuidado das crianças e sua emancipação. Para que o Estatuto não esteja mais uma vez em risco (BAZÍLIO, 2003), é necessário, hoje, retomar essa luta de modo a garantir recursos financeiros e gestão competente na proteção e cuidado com a infância.

0 objetivo deste texto é discutir as relações entre cuidado e direitos das crianças, a partir dos resultados de um estudo desenvolvido por um grupo de pesquisa interinstitucional, do qual participaram alunos e professores de duas universidades. As contribuições deste estudo são aqui apresentadas no sentido de problematizar, inquietar e, se possível, afetar modos de pensar e de agir em instituições comprometidas com as conquistas do ECA.

\section{Direito, liberdade e proteção: faces do cuidado}

A construção de uma nova forma de olhar a criança - a criança cidadã - expressa na Constituição Federal (BRASIL, 1988) só foi possível graças à força de um movimento social, que conseguiu se introduzir no processo constituinte e se fazer presente a partir de uma emenda popular, recordista em número de assinaturas - mais de um milhão e duzentos mil signatários, de todas as unidades da Federação. Liderada pelo Movimento Nacional Criança e Constituinte ${ }^{3}$, essa articulação inseriu as crianças no mundo dos direitos humanos, um marco para o lançamento de princípios e de implementação de novas políticas para a infância (CRAIDY, 1994). Segundo Fernandes (1989, p. 87):

3- Movimento que articulou o setor público federal, a partir de diversos ministérios, com mais de 600 organizações não governamentais. 
Por várias vias, gente de diversas categorias sociais, profissionais, étnicas e raciais surge no centro do palco e assume o papel de agente, de senhor da fala. Um indígena, um negro, um portador de defeito físico, um professor modesto, saem da obscuridade e se ombreiam com os notáveis, que são convidados por seu saber ou lá comparecem para advogar as causas de entidades mais ou menos empenhadas na autêntica revolução democrática.

Pesquisadores sensíveis à situação das crianças aderiram ao movimento e se fizeram protagonistas de um diálogo com o Instituto Nacional de Estudos e Pesquisas Educacionais Anísio Teixeira/MEC e com os principais órgãos de fomento à pesquisa, não só para viabilizar a disseminação de conhecimentos produzidos em diferentes áreas acerca das crianças, mas também para induzir novas pesquisas a respeito da educação da criança pequena e os instrumentos metodológicos para desenvolvê-las.

Barreto (1994), Tiriba (1992), Rosemberg (1994), Campos e Rosemberg (1995), Kramer (1982, 1994), Rosseti-Ferreira (1988), Rocha (1999) e Faria (1999) são alguns entre tantos que colaboraram para fundamentar esse novo olhar legal e tecer recomendações para os programas e as políticas no âmbito das creches e pré-escolas.

$\mathrm{Na}$ década de promulgação do Estatuto da Criança e do Adolescente, o Brasil convivia com $20 \%$ das crianças fora da escola. Hoje, trinta anos depois, as taxas foram reduzidas para 4,7\% (UNICEF, 2019). Concorreram para essa redução várias formas de mobilização social, ações, projetos e programas governamentais que almejaram um país menos desigual. No âmbito das políticas públicas de educação, a ampliação do Ensino Fundamental para 9 anos, o aumento da idade escolar obrigatória da educação básica para a faixa entre 4 e 17 anos de idade e os planos de educação contribuíram para esse decréscimo que tem valor ainda maior quando se analisa a magnitude dos números - há 21 milhões e 500 mil crianças de 0 a 6 anos, em 2020. São números que ultrapassam a população de mais de 40 países da Europa (entre eles Portugal, Bélgica, Holanda, Áustria), da América (Chile, Equador, Paraguai, Uruguai, Bolívia), entre outros continentes.

Os estudos de Campello et al. (2018), ao colocar uma lupa sobre os 5\% e os 20\% mais pobres da sociedade brasileira entre os anos de 2002 a 2015, concluem que houve um processo de inclusão e redução de parte importante das desigualdades ocorridas no país - saúde, renda, habitação e educação. Fruto de decisão política, e, por isso, "afastam a aceitação de uma condenação natural e inevitável à desigualdade” (CAMPELLO et al., 2018, p. 65). De qualquer forma, é preciso avançar no sentido de garantir igualdade entre crianças e um dos principais aspectos levantados pelas pesquisas (ABRAMOWICZ, 2013; GOBBI, 2018) é a desigualdade de origem determinada pelo município de nascimento das crianças onde nem todas têm as mesmas condições de acesso e de qualidade à Educação Infantil.

Rosemberg e Mariano (2010), ao revisitarem a literatura acerca das repercussões da Convenção Internacional sobre os Direitos da Criança no Brasil (1989), mostram a tensão entre o debate sobre direitos de liberdade e de proteção - pouco estudados no Brasil, mas presentes no campo jurídico, como o Estatuto da Criança e do Adolescente. Reforçam a ideia de que a Convenção tem uma pretensão universal, embora com um viés ocidental, com ênfase nos direitos individuais (de cidadania) e, numa tentativa de "conciliar as correntes protecionista e liberacionista vistas por muitos como antagônicas 
e/ou inconciliáveis" (MARCHI; SARMENT0, 2017, p. 955), traz em seu bojo tanto os direitos à proteção e provisão quanto os direitos de liberdade, expressão e participação. 0 debate estrutura-se, por um lado, na problematização da categoria infância no singular e, por outro, nas vulnerabilidades presentes nesse grupo etário; não só pela especificidade decorrente da faixa etária, mas também pelas condições estruturais que esse grupo ocupa, fruto da posição socialmente subordinada da infância. 0 art. 227 da Constituição Federal, que expressa o paradigma do Estatuto, é emblemático nesse debate:

É dever da família, da sociedade e do Estado assegurar à criança, ao adolescente e ao jovem, com absoluta prioridade, o direito à vida, à saúde, à alimentação, à educação, ao lazer, à profissionalização, à cultura, à dignidade, ao respeito, à liberdade e à convivência familiar e comunitária, além de colocá-los a salvo de toda forma de negligência, discriminação, exploração, violência, crueldade e opressão. (BRASIL, Art. 227, 1988).

Sabe-se que a concretização de direitos de liberdade e de proteção ultrapassam as relações cotidianas, pois são as instituições sociais que vão ressignificar as palavras e traduzilas em atos, normas e formas de aceitação do outro, influenciadas pelo lugar que a infância ocupa na sociedade, que dão o contorno sobre o modo com que as crianças serão tratadas e, consequentemente, como os adultos irão enxergá-las. É nesse sentido que Didonet (2015) argumenta que em relação ao direito de a criança ser ouvida, o ECA é acanhado e expressa menos do que foi postulado na Convenção dos Direitos da Criança, pois:

[...] não é só o adulto que fala, seja ele o pai, a mãe, o cuidador, o conselheiro tutelar, o juiz... Não são apenas eles que têm voz, interpretação e decisão sobre os assuntos de interesse da criança. Também ela tem o que dizer e deve ser ouvida. (DIDONET, 2015, n. p).

A argumentação é sustentada por trabalhos pioneiros no Brasil a respeito do cuidado e que, em alguma medida, impactaram os documentos oficiais. Campos e Rosemberg (1995), Craidy (1994), Kramer (2003) Faria (1999), Montenegro (2001) e Tiriba (2005), entre outros, foram fundamentais para trazer o tema para a realidade do trabalho com as crianças na Educação Infantil, articulando educação e assistência, também entendida como direito, muito além da visão assistencialista de guarda ou tutela. Movimentos sociais, pesquisadores e profissionais de educação buscavam concepções teóricas de modo a aprofundar propostas políticas e alternativas práticas.

0 cuidado está presente nos textos base que norteiam a Educação Básica no Brasil, tanto no Estatuto da Criança e do Adolescente (BRASIL, 1990) quanto na Lei de Diretrizes e Bases da Educação Nacional (BRASIL, 1996). Os documentos apontam a inseparabilidade entre educar e cuidar. Antes compreendida como especificidade da Educação Infantil, essa junção aparece como fundamento de toda a educação básica.

Nos últimos anos, resultados dos estudos desenvolvidos a partir dessa temática apontam o desafio de romper com uma perspectiva instrumental na qual o cuidar complementaria o educar. Tais estudos contribuem para uma fundamentação teórica alicerçada na concepção de cuidado que extrapola a dimensão instrumental - dar banho, 
alimentar, criar hábitos, colocar para dormir - e se aproxima de uma perspectiva ética e humana, de modo a contribuir para uma concepção de educação como encontro da criança com o adulto, como uma experiência compartilhada (GUIMARÃES, 2010; 2011).

Pouco a pouco, diversas pesquisas teóricas e empíricas favorecem uma compreensão do cuidar e do ser cuidado como algo inerente às relações humanas no cotidiano das instituições educativas (BORGES; SCRAMINGNON; CASTR0, 2016). A pesquisa que origina este texto, apresentada a seguir, converge com essa abordagem.

\section{O cuidado como ética: a pesquisa realizada}

0 discurso acerca do cuidado, presente nos documentos legais, traduz-se em práticas, atos e normas dentro das instituições de educação marcadas pela concepção de criança que delimita como os adultos enxergam as crianças e como se relacionam com elas. E, no movimento dialético e dialógico das relações sociais, as práticas alimentam e reorientam concepções teóricas. Contudo, a observação das interações entre adultos e crianças nas instituições educativas evidencia, muitas vezes, um contexto de pouco cuidado, de pouco diálogo, que compromete os vínculos e a qualidade das relações.

Esta pesquisa teve como objetivo conhecer e problematizar a qualidade dessa relação entre as crianças e os adultos nas escolas - as marcas do cuidar e ser cuidado. A investigação voltou-se para práticas positivas de cuidado, identificadas a partir de critérios de familiaridade, ou seja, a partir da indicação ou sugestão de profissionais da área. Foram observadas interações em seis instituições públicas municipais (duas creches; duas pré-escolas; duas escolas de Ensino Fundamental) que atendem da Educação Infantil ao Ensino Fundamental. A partir das observações, definiram-se os sujeitos da pesquisa: profissionais e familiares contaram suas histórias em entrevistas individuais e coletivas; as crianças foram ouvidas em oficinas de literatura.

Os principais critérios de escolha das instituições foram: a indicação de boas práticas, a familiaridade e o interesse de profissionais que trabalhavam nas instituições em participarem da pesquisa. Por boas práticas foram entendidas aquelas que - nas creches, pré-escolas e escolas - colocam a criança na centralidade das suas ações educativas e trabalham na perspectiva da ampliação cultural. Entretanto, quanto ao critério da familiaridade, foi preciso combiná-lo com outra referência: o IDEB ${ }^{4}$. Foram selecionadas, entre as escolas com índice mínimo até 7 , aquelas com localização viável - considerando as condições de acesso, a distância e a segurança - dado que os/as pesquisadores precisariam se locomover até elas muitas vezes ao longo da pesquisa. Após visitas a dez instituições, foram definidas as seis que se tornaram o foco, todas elas públicas municipais.

Assumindo a escuta como central para conhecer as histórias de vida dos sujeitos pesquisados, os objetivos específicos foram: (1) identificar histórias de vida de crianças e adultos; (2) conhecer interações cotidianas e práticas sociais e culturais que emergem

4- Índice de Desenvolvimento da Educação Básica, criado em 2007, pelo Instituto Nacional de Estudos e Pesquisas Educacionais Anísio Teixeira (Inep), formulado para medir a qualidade do aprendizado nacional e estabelecer metas para a melhoria do ensino. Disponível em: http://portal. mec.gov.br/ 
nas narrativas das histórias de crianças, famílias e professores; e (3) delinear aspectos de aproximação e afastamento entre narrativas das crianças, suas famílias e professores/as.

A pesquisa pretendeu ainda colaborar para a construção de um olhar crítico das concepções e relações de cuidado do outro e de si na Educação Infantil e no Ensino Fundamental, em especial quanto à responsabilidade dos adultos pelas crianças nas instituições e famílias. Teve como meta fornecer subsídios para políticas públicas comprometidas com a qualidade das relações entre adultos e crianças nas instituições educacionais, bem como para a formação de profissionais que atuam com bebês e crianças, o que a conecta ao debate em torno do Estatuto da Criança e do Adolescente.

0 conceito de cuidado em suas múltiplas dimensões foi construído, na pesquisa, a partir da aproximação com o conceito de diálogo proposto por Buber $(1977 ; 2001$; 2009) na busca por um olhar de reconhecimento, aceitação e compreensão do outro, além de presença, encontro e reciprocidade.

Para Buber (2009), na relação com o outro, o diálogo pode ser autêntico, técnico ou um monólogo disfarçado de diálogo. No diálogo autêntico, as pessoas que dele participam se fazem presentes, há a intenção de ouvir o outro e não apenas falar. Os participantes estão comprometidos uns com os outros e voltam-se uns aos outros. Enquanto o diálogo técnico é "movido pela necessidade de entendimento objetivo" (BUBER, 2009, p. 54) e os participantes mantêm uma conversação a fim de se ter uma explicação objetiva sobre algo. Por outro lado, no monólogo disfarçado de diálogo o outro não é considerado, não é reconhecido e sua presença é indiferente, é um "fantasma sem rosto" (BUBER, 2009, p. 54).

Partindo desse pressuposto e das formas do diálogo apresentadas por Buber (2009), o cuidado foi pensado pelo viés dialógico e, assim, a partir das situações observadas nas práticas de professores - e demais profissionais - e da escuta dos mesmos, foram levantadas as categorias de pesquisa, assim definidas: (i) cuidado autêntico, entendido como interesse pelo outro, não indiferença, responsividade; (ii) cuidado técnico, que se propõe a informar, ensinar, convencer alguém ou, simplesmente, transmitir uma mensagem; (iii) descuido, em que o outro não é considerado, não é reconhecido e sua presença é indiferente; e (iv) descuido disfarçado de cuidado, em que a atitude tem formato de cuidado, mas esconde uma indiferença em relação ao outro.

Algumas categorias que emergem das entrevistas com os professores, com as famílias e com as crianças contribuem para a discussão do cuidado como direito a partir das concepções expressas nas narrativas desses diferentes sujeitos.

Nesta pesquisa, adultos e crianças foram colocados no centro da cena. Foram realizadas 34 entrevistas: 20 entrevistas com profissionais; oito entrevistas com familiares (avós, mães e madrinha) e seis oficinas realizadas com as crianças que frequentam a Educação Infantil e séries iniciais do Ensino Fundamental. A ampliação da rede familiar foi introduzida pelo olhar das crianças, que nas oficinas deram destaque às avós e madrinhas nas relações de cuidado, destacando a presença feminina nos cuidados às crianças. Tanto na docência quanto nas relações familiares, o universo feminino marca as ações de cuidado na vida das crianças que frequentam as instituições pesquisadas. Para fins deste artigo, foram analisadas entrevistas feitas com quatro docentes; quatro familiares (três mães e uma avó) e sete crianças. 
As oficinas com as crianças tiveram a literatura como convite para o diálogo. A opção por livros literários deu-se para favorecer a unidade das estratégias metodológicas adotadas nos diversos campos, já cada instituição mostrava diferentes relações de cuidado. Com essa escolha, o cuidado foi não só como tema da pesquisa, mas escolha metodológica: a literatura e a arte sensibilizaram e abriram a possibilidade de caminhos partilhados pelos pesquisadores com as crianças, o que favoreceu o encontro entre esses sujeitos e o espaço para um diálogo autêntico. ${ }^{5}$

Nos itens a seguir, procuramos dar visibilidade ao que ouvimos de professores, familiares e crianças que frequentavam as seis instituições. Vale notar que os nomes citados são fictícios e após cada relato está indicado se se trata de professoras/es, familiares ou crianças e se frequentam ou trabalham em creche (C), pré-escola (PE) ou escola (E).

\title{
O que dizem adultos e crianças?
}

Considerando que a narrativa não é pontual nem linear, e que a rememoração é também a arte de contar de novo, as entrevistas foram tomadas no sentido dialógico, com foco na construção e reconstrução de sentidos mais do que a aplicação de perguntas que buscassem respostas exatas para indagações diretas. Tanto nas entrevistas com crianças quanto com adultos, a questão ética se impôs. Envolvendo situações de cuidar e ser cuidado, as entrevistas trouxeram memórias de situações que exigiram respeito e conduta do pesquisador coerentes com os objetivos e o referencial da pesquisa, bem como respeito à singularidade da narrativa do entrevistado, criança ou adulto.

0 referencial teórico-metodológico baseia-se em Buber e os conceitos de vínculo, confiança e presença; cuidar e ser cuidado. As histórias de vida foram a opção metodológica, abordagem com tradição no campo da pesquisa sociológica e nas pesquisas em educação voltadas para a produção de um conhecimento que não dicotomiza vida pessoal e profissional, sujeito e objeto, cotidiano e história.

\section{0 que dizem os professores?}

As entrevistas e observações dos profissionais foram organizadas nas categorias: cuidado autêntico (subcategorias cuidado de si e cuidado como ofício); cuidado técnico; descuido; descuido disfarçado de cuidado.

0 cuidado autêntico expressou-se como cuidado de si e o cuidado como ofício. 0 cuidado de si mostrou-se em relação a diferentes aspectos.

\begin{abstract}
Ah, eu acho que eu cuido de mim quando me permito comer alguma coisa gostosa (risos), [...] quando tenho um tempo para mim, às vezes dormir até mais tarde quando posso, quando quero ficar em casa sem fazer nada. Eu acho que isso é cuidar de mim [...] quando eu vou ao salão de beleza. A gente cuida da gente de várias formas. Tem umas formas mais regradas, mais chatas [...] como com a alimentação. Às vezes não quero comer tão certinho, mas sei que aquilo faz bem
\end{abstract}

5- Todas as estratégias metodológicas obedeceram rigorosamente aos procedimentos éticos estabelecidos para a pesquisa científica. 0 anonimato dos sujeitos da pesquisa e das instituições está garantido. 
para mim. Quando eu estou estressada e como um brigadeiro é também cuidar de mim. (Naiara, Profa C, Entrevista nov. 2017).

Em sua narrativa, a professora relaciona os critérios que determinam se está cuidando de si e sugere que cuidar nem sempre é fazer o que é correto, mas praticar ações que promovam o bem estar, supram uma necessidade pessoal (saciedade de um desejo, autoestima) ou contemplem a espiritualidade, como diz outro professor.

Eu pratico arte marcial que acelera e que freia e tem uma outra que, o Tai Chi, dá uma acalmada, entendeu... e a espiritualidade. Eu acho que o caminho que eu adotei para desenvolver a minha espiritualidade acaba me formando também como pessoa e contribui muito nesse sentido, de enxergar o outro de uma determinada forma, de partir de um determinado lugar. (Tomás, Prof. PE, Entrevista ago. 2017).

Aqui uma questão é levantada: é preciso estar bem consigo mesmo para cuidar do outro? Os dois relatos lembram Buber (2011, p. 38), quando propõe: "começar consigo, mas não terminar consigo: partir de si, mas não ter a si mesmo como fim”. 0 caminho aponta para um movimento, um engajamento em que o destino não está claro. Nesse caminho, é necessária a autocontemplação, a tomada de consciência, o pensamento no “eu próprio”. É importante se ver, encontrar o seu caminho, cultivar a solidão, mas não acabar consigo mesmo, mantendo a relação com o outro, com a comunidade. A condição para entrar no diálogo é encontrar o eu, mas o eu que está em relação.

Esse cuidado de si abre-se para outra subcategoria, o cuidado como escuta do outro, ponto de partida para a entrega, a relação com inteireza e reciprocidade, como pode ser visto no relato a seguir, que é escuta e acolhimento.

Hoje eu dei banho. Tem criança que quer contar da mãe, da tia, que foi na festa, no tempo que eu estou aqui tentando correr um pouquinho com o tempo. Mas ao mesmo tempo eu tenho que ter esse respeito por ela, pela criança, que está querendo aquele momento; porque no banho você tem uma série de coisas maravilhosas. (Rosa, Profa. C, Entrevista nov. 2017).

Cuidar é, pois, exercício de acolhimento do outro em suas necessidades e possibilidades; é encontro nas situações cotidianas da vida em que o interesse pelo outro atravessa a futilidade do momento e se estabelece a relação. Falando do tempo com a criança como oportunidade de dar o melhor de si, outra professora diz: "Dar o melhor de si, prestar a atenção no outro, ver como você pode de alguma forma melhorar a qualidade daquela criança no momento em que você está com ela, que você está em um momento, um tempo muito curto com elas.” (Antônia, Profa. E, Entrevista out/2017).

A escuta dos professores apontou, também, para o cuidado como ofício, próprio da função exercida no desempenho da atividade profissional com responsabilidade e responsividade, em presença. 0 cuidado autêntico não exclui o cuidado técnico, mas o amplia, pois é visto como parte do ofício do professor, um saber a ser construído pelo professor e com as crianças. Quando entendido como ofício do professor, o cuidado técnico 
é parte do cuidado autêntico. A fala a seguir sinaliza o autoconhecimento necessário para o exercício profissional com as crianças, respeitando suas singularidades.

\begin{abstract}
Vamos supor: está acontecendo lá, o caos veio nos visitar, então aí alterou o tom de voz. A partir do momento que deu aquele impacto, aí vem o cuidado. Porque nunca é uma alteração do estado que eu estou sentindo. Não posso me sentir tomado de raiva ou de orgulho, ou de qualquer coisa [...]. A criança vem e começa a medir força comigo; se eu sou tomado por qualquer coisa no sentido de raiva e começo a entrar em um estado parecido com o dela, não faz sentido eu estar aqui na função de professor. (Tomás, Prof. PE, Entrevista ago. 2017).
\end{abstract}

0 professor refere-se às emoções que sente no cotidiano com as crianças. Reconhece os sentimentos que o tomam no dia-a-dia, legitima, mas relata que não pode ser impulsivo e ser mobilizado por isso. Comenta que cenas como essa são comuns e o adulto precisa controlar seus impulsos e atuar do lugar de adulto, de professor. Perder a cabeça não faz parte do ofício do professor. Perder a cabeça é ficar em outro lugar. A resistência aparece no cuidado como ofício, o cuidado como ato. Eu penso e faço, atuo. Para Buber (1977, p. 56) a relação é "palavra ato com a força instauradora do ser."

Não posso experienciar ou descrever a forma que vem ao meu encontro; só posso atualizá-la. [...] e for submetida ao critério da objetividade, a forma não está realmente "aí"; entretanto, o que é mais presente do que ela? Eu estou numa autêntica relação com ela; pois ela atua sobre mim assim como eu atuo sobre ela. (BUBER, 1977, p. 56).

A palavra ato traz uma implicação com o outro. É expressa no encontro, é responsabilização pela vida, como aponta Pena (2019). Cuidar exige atenção ao outro. Esse movimento é estar em presença, é contemplar o outro que está diante de si; é ato educativo comprometido com o outro e contribui para a sua formação humana.

\title{
0 que dizem os familiares?
}

Cuidado é muito mais que o básico como só levar para escola, só dar um banho, só dar comida, e só cuidar das coisas materiais. Cuidado é mais do que isso, é carinho e atenção. As crianças precisam de atenção e carinho, mais de presença do que de presentes. (Ana, Mãe PE, Entrevista set. 2018).

Cuidado como presença. Na fala, precisa-se mais de presença do que de presentes. Cuidado que não cuida apenas de coisas materiais, banho, comida, mas que oferta atenção e carinho. Cuidado como algo colado na relação humana, no reconhecimento da humanidade do outro, da humanidade de si no outro e da necessidade do outro.

Cuidado como uma ação ética no cotidiano; como respeito ao espaço do outro. Cuidado como não invasão do espaço do outro; como atenção ao tempo do outro, como reciprocidade. 0 cuidado como modo de ser, estar e fazer no/o mundo. Cuidado que é presença, como um modo de olhar, lugar do sensível. Cuidado como lugar que se dá no afeto, como um lugar para se existir; como encontro. 
Para que a presença seja possível e resista às exigências da rotina diária de cumprimento de tarefas e vigilância sobre as crianças é necessária uma rede de apoio. Como conciliar a necessidade de trabalho dos adultos, as tantas tarefas dentro e fora de casa que lhes exigem tempo, e o cuidado das crianças?

Hoje [...] eu deixo ela na escola sete e meia da manhã, vou para o trabalho e volto às oito. Mas também se eu não fizer isso... Como você falou, cada história é uma história. Se eu também não fizer isso, eu não consigo fazer outras coisas para elas [...]. Esse cuidado precisa ser compartilhado com outras pessoas. Até com a mais velha, que leva no inglês. 0 dia, por exemplo, que ela fica no reforço de tarde. Às vezes a escola liga e diz vai ter que vir buscar porque não vai ter reforço. A gente fala “Joana, pelo amor de Deus, vai na escola”. Então, o cuidado hoje é de todos da casa. (Iara, Mãe E, Entrevista out. 2018, grifos nossos).

0 apoio da família é mencionado em vários relatos. Pai, avó, tio, madrinha, irmãos... Quantos hoje podem contar com essa proximidade? Os desafios mobilizam estratégias e recursos. A distância geográfica, porém, não é empecilho. "Sempre tinha alguém em volta”, diz Daniele. E continua:

É como eu falei, a família tem uma convivência muito boa. Somos três mulheres, então toda criança que nasce a gente vai abraçando, meu filho não é só meu, é meu e das minhas irmãs. (Daniele, Mãe PE, Entrevista set. 2018, grifos nossos).

Como alternativa para atender a necessidade de cuidado técnico, a rede de apoio familiar implica confiança, relações de pertencimento, aproxima gerações de uma família, extrapola o técnico. Em destaque, as avós.

0 que eu acho assim importante é que o neto ele ficou lembrando "Vovó, tem reunião para você lá na escola”, como ele vê que eu trato ele e cuido dele. Essa semana, eu achei muito bonitinho que eu operei e não estava podendo fazer as coisas. Ele ontem falou para mim: "Vovó, deixa que eu vou botar minha comida e você fica aí; não faz nada não, que eu que vou cuidar de você”. E desde que eu cheguei do hospital ele está cuidando de mim. Então é isso. 0 retorno. Quando a mãe não pode ensinar o dever, ele vai lá, eu ensino. (Marisa, Avó E, Entrevista out. 2018).

As avós foram entrevistadas por sugestão das crianças. Narrativas de avós e netos revelam esse cuidado intergeracional de doação, proteção, presença e inteireza. 0 cuidado que gera reconhecimento no outro fortalece o vínculo pela necessidade da rede de apoio familiar. Nem todas as crianças têm avós vivos ou próximos, mas esse cuidado é citado pelas entrevistadas como especial.

\section{0 que dizem as crianças?}

Escutar as crianças, buscar compreender suas narrativas, ações e modos de entender o mundo foi uma prática teórica, política e pedagógica dos anos que resultaram na aprovação do Estatuto. Esse respeito e reconhecimento vêm sendo perseguidos na pesquisa, 
nas políticas e nas práticas desde então, como mostram os estudos de Delgado; Muller (2005), Cruz (2008), Sarmento e Gouveia (2008), Abramowicz e Henriques (2018), Nunes e Corsino (2019), entre muitos outros desenvolvidos no Brasil. Também na investigação aqui apresentada essa foi uma preocupação central.

Os relatos das crianças apontaram a necessidade de se criar - encontrar, deduzir ou (re)definir - categorias além daquelas que emergiram nas entrevistas com os adultos, professores e familiares. Esse trabalho foi realizado em diálogo com os referenciais teóricos, uma vez que aquilo que as crianças entendem como cuidado ora se aproxima das concepções dos adultos, ora refere-se às experiências infantis de recriar, de reinterpretar o mundo e de fazer referência à cultura de pares (CORSAR0, 2011).

A análise inicial das categorias relativas às relações das crianças com o cuidado deu-se por temas que emergiram do estudo teórico e das entrevistas com os adultos, como cuidado na relação das crianças com os adultos; cuidado dos adultos com as crianças; cuidado consigo mesmo; cuidado entre as crianças (a relação entre irmãos, o cuidado e a brincadeira, o cuidado e a amizade).

Mas outros caminhos mais instigantes emergiram do campo: em uma instituição, as crianças do primeiro ano do Ensino Fundamental apontaram uma professora como a que lhes dedicava cuidados - as crianças deram visibilidade a essa professora e contaram o que é cuidado para elas; em outra, as pesquisadoras identificaram as merendeiras como as pessoas que tinham atitudes mais cuidadosas. Porém, o principal caminho foi o de definir categorias a partir das entrevistas com as crianças de cada instituição.

A opção pela literatura foi um modo de dar unidade às estratégias metodológicas no trabalho de campo. As instituições têm diferentes relações de cuidado entre as crianças, com os objetos (brinquedos, materiais), entre crianças e adultos (merendeiras, professoras, familiares). A literatura mediou as interações entre pesquisadores e crianças, tornando possível observar e ouvir as relações de cuidado nas narrativas das crianças, seu vínculo com os adultos e seu modo de ver o cuidado como proteção, presença, sutileza.

A pesquisadora pergunta às crianças se cuidam de alguém: "Marta - Eu cuido da minha avó. Às vezes, quando ela coloca os brinquedos na caixa errada, eu tiro (Crianças E, Oficina, jul. 2018).

Aqui, a criança fala de cuidado como atenção e expressa seu cuidado com os adultos. Ela não aponta o erro da avó, mas acolhe o erro: a avó, na sua maneira de falar, colocou o brinquedo na caixa errada, porque a avó não sabe, por desconhecimento.

Em uma das escolas de Ensino Fundamental, as crianças do quinto ano conversam e falam, além da atenção, do cuidado como carinho:

Andreia: Cuidar é dar carinho, atenção, amor, ler a agenda da criança todo dia, conversar sobre como foi o dia na escola, olhar o estojo da criança, ajudar a fazer os trabalhos de casa.

Bruna: Eu acho que a mãe deve agir certo e não pode fazer coisa errada. Mãe não tem que xingar o filho. Minha mãe não é assim. Ela me ajuda, faz carinho...

Camila: Fazer comida para o filho é uma forma de cuidar. Fazer a janta assim que chega do trabalho para o filho. (Crianças E, Oficina ago. 2017). 
As crianças denunciam os adultos e, assim fazendo, elas mostram que, apesar de já serem crianças maiores, desejam o cuidado do adulto. Trata-se do cuidado traduzido em ações como ver o estojo, ler uma história, estar junto. Falam também do que não acontece com elas, do que falta para elas ou para os amigos. As crianças falam, portanto, de outro lugar, reproduzindo as falas dos adultos a partir do que compreendem. As falas das crianças estariam apontando a invisibilidade dos filhos para os pais?

Há situações nas quais as crianças falam do cuidado como ofício do professor.

Pesquisadora: Como vocês acham que uma criança pode se sentir cuidada por alguém?

Daniel: Quando a professora não apaga o dever do quadro. (Crianças E, Oficina ago. 2017).

0 cuidado aqui está em algo simples do cotidiano escolar, que tem importância para a criança. Esse modo de ver permite evocar a perspectiva de cuidado e educação que em Buber (2009) é ato responsável que supre a necessidade do outro, visa ao bem estar e à felicidade. A responsabilidade só existe onde existe o responder verdadeiro diante de acontecimentos do cotidiano, diz Buber (2009), o que parece nesse caso ter valor para a criança.

As crianças falaram das avós como pessoas que cuidam, assim como as avós relataram que cuidam das crianças. Mas a figura do pai também esteve presente.

Ana Júlia - 0 meu pai é legal, porque ele é engraçado. Ele sempre faz coisas engraçadas. Ele sempre brinca com a gente.

Pesquisadora - E você acha que brincar é cuidar?

Ana Júlia - É, o meu pai cuida de mim.

Sofia - 0 meu pai toda hora quando ele vai ao shopping ele leva a gente.

Pesquisadora - E quando seu pai leva você ao shopping ele está cuidando de você?

Sofia - Não. Ele sempre fica me olhando, para ninguém me pegar, nenhuma pessoa má. (Crianças

E, Oficina jul. 2018).

0 cuidado como brincadeira revela, mais uma vez, a potência da presença do adulto, no olhar das crianças. Sem saberem ainda dimensionar os riscos que correm diante de "uma pessoa má", as crianças parecem identificar mais a brincadeira como cuidado - em sintonia com sua necessidade como crianças - do que a vigilância, a atenção, o olhar voltado pelo adulto para a segurança que, com certeza, para a presente pesquisa, indicam sim o cuidado como responsabilidade do adulto pelas crianças.

\section{Ainda algumas reflexões}

0 tempo da ação - seja de pesquisa, da política ou da prática - é diferente do tempo da escrita. 0 contexto complexo em que se deu a produção do presente texto se agudizou. Ao finalizá-lo, não há como prever concretamente o cenário em que se dará a leitura, nem dimensionar as perdas de saúde, de vidas, empregos e salários, de projetos, de direitos. Mas serão profundas e graves. As condições econômicas e políticas do país acentuam o risco institucional da democracia. 
Para enfrentar o risco, são instrumentos fundamentais, de um lado, as conquistas da dimensão macro, como a Constituinte de 1988, o Estatuto da Criança e do Adolescente, as políticas públicas voltadas à justiça social, contra a desigualdade, a exclusão, o preconceito; de outro lado, as conquistas cotidianas, da dimensão micro, que se dão a conhecer por relatos de experiência, de práticas, de histórias de vida. Em todos os casos, a pesquisa tem o papel central ao desvelar ganhos, necessidades, desvios, distorções.

0 Estatuto da Criança e do Adolescente (BRASIL, 1990) inseriu as crianças e os adolescentes no universo dos direitos humanos, contribuindo para uma concepção de criança cidadã. Trinta anos após a publicação do ECA, em tempos em que - por razões políticas - as conquistas estão em risco, se faz urgente cuidar das infâncias.

A situação de desigualdade da população é agravada pela falta de acesso a equipamentos sociais que garantam saúde pública, educação e cultura. Crianças e adolescentes, pela sua vulnerabilidade, sofrem ainda mais pela violência doméstica que, com uma face perversa muito aquém da dignidade humana, afeta todas as classes sociais, mas, sobretudo as crianças mais pobres.

Hoje é mais do que necessário estar vigilante ao ECA. Temos lido e assistido a pronunciamentos de conselhos de educação dos municípios brasileiros que no jogo político, por influência de grupos com interesses privados, acabam por induzir a oferta de atividades pedagógicas e/ou desenvolvimento de conteúdos de forma remota, para creches e pré-escolas, enquanto o isolamento social perdurar. 0 próprio Conselho Nacional de Educação lançou no dia 17 de abril de 2020 uma consulta acerca da reorganização dos calendários escolares e a realização de atividades pedagógicas não presenciais durante o período de pandemia, de modo a sugerir a oferta de Educação Infantil na modalidade de ensino à distância. As propostas expressam que o desafio de romper com uma perspectiva instrumental na qual o cuidar complementa o educar continua em curso, a despeito da legislação e dos estudos desenvolvidos reforçarem o contrário.

0 movimento social, mais uma vez, tem sido importante para reafirmar as conquistas e para mostrar que as escolas são um equipamento público e, por isso, têm um papel social de apoio às famílias, de diversas formas, de respeito às diferenças e à vida privada. A vida não pode ter um valor menor nem tampouco a perspectiva ética e humana pode perder terreno para conhecimentos pouco afetos à formação humana.

O Movimento Interfóruns de Educação Infantil do Brasil veio a público defender que o não cumprimento da frequência, bem como o não cumprimento da carga horária anual dos bebês e crianças em creches e pré-escolas não trará prejuízos maiores do que os já causados pelo avanço da Covid-19. Considera que a função social atribuída pela LDB 9.394/96 à educação infantil, ratificada pelas normativas do próprio CNE, compreende creches e pré-escolas como espaços coletivos não domésticos - o que prevê que as experiências vivenciadas nas instituições de educação infantil são, em grande medida, distintas das vividas no contexto familiar. É importante lembrar que temos crianças, também, no Ensino Fundamental e que elas precisam ser cuidadas, acolhidas e protegidas no atual contexto da pandemia, quando estão sobrecarregadas de tarefas escolares e expostas a um tempo excessivo de uso de telas ou excluídas pela falta de acessibilidade. 
Nesse contexto, dois temas ficam abertos à reflexão e são desafios à ação: a centralidade do cuidado na esfera humana e a urgência da mobilização no momento presente. 0 cuidado - de si, do outro, de todos - em especial das crianças - é uma questão de sobrevivência. Esse é um dos aspectos que emerge da pesquisa apresentada. A ética do cuidado é exigência para que a nossa esfera humana - nossa humanidade - não seja destruída. Ela significa presença do adulto, reciprocidade, vínculo, encontro.

A mobilização - de pessoas, grupos, de instâncias públicas e privadas, instituições, coletivos, sindicatos, associações, organizações, movimentos sociais - é necessária para que essa ética do cuidado se torne fato, e não só intenção.

Cuidado e mobilização são atuais, porque devem atuar de modo forte.

\section{Referências}

ABRAMOWICZ, Anete; HENRIQUES, Afonso Canella (org.). Educação Infantil: a luta pela infância. Campinas: Papirus, 2018. 288 p.

ABRAMOWICZ, Anete; VANDENBROECK, Michel. Educação Infantil e diferença. Campinas: Papirus, 2013. $192 \mathrm{p}$.

BARRET0, Angela Maria Rabelo Ferreira. Por que e para que uma política de formação do profissional da educação infantil? In: BRASIL. MEC/SEF/COEDI. Por uma política de formação do profissional de Educação Infantil. Brasília, DF, 1994. p. 11-15.

BAZÍLIO, Luiz Cavalieri. 0 Estatuto da Criança e do Adolescente está em risco: os conselhos tutelares e as medidas socioeducativas. In: BAZÍLIO, Luiz Cavalieri; KRAMER, Sonia (org.). Infância, educação e direitos humanos. São Paulo: Cortez, 2003. p. 35-58.

BENJAMIN, Walter. Obras escolhidas I: magia e técnica, arte e política. São Paulo: Brasiliense, 1987. 272 p.

BORGES, Leonor Pio; SCRAMINGNON, Gabriela; CASTRO, Marina. Levantamento bibliográfico: uma leitura sobre o tema do cuidar e ser cuidado no campo da educação. In: SEMINÁRIO DE GRUPOS DE PESQUISA SOBRE CRIANÇAS E INFÂNCIAS (GRUPECI), 5., 2016, Florianópolis. Anais... Florianópolis: 2016. Disponível em: <https://grupoinfoc.com.br/publicacoes/congressos/c53_SCRAMINGNON_G_B_S_Souza_M.P.C_ TOLEDO_L_P_B_Levantamento_bibliografico_uma_primeira_leitura_sobre_0_tema_do_cuidar_e_ser_ cuidado_no_campo_da_educacao.pdf.> Acesso em: 20 jul. 2020.

BRASIL. MEC/SEB. Conselho Nacional da Educação. Câmara Nacional de Educação Básica. Diretrizes Curriculares Nacionais Gerais da Educação Básica. Brasília, DF: MEC: SEB: DICEI, 2013.

BRASIL. Lei no 8.069, de 13 de julho de 1990. Dispõe sobre o Estatuto da Criança e do Adolescente e dá outras providências. Diário Oficial da República Federativa do Brasil, Brasília, DF, 16 jul. 1990. Disponível em: http://www.planalto.gov.br/ccivil_03/LEIS/L8069.htm\#art266. Acesso em: 20 jul. 2020.

BUBER, Martin. Do diálogo e do dialógico. São Paulo: Perspectiva, 2009. 
BUBER, Martin. Eu e tu. Tradução e introdução de Newton Aquiles Von Zuben. São Paulo: Moraes, 1977. $152 p$.

BUBER, Martin. 0 caminho do homem segundo o ensinamento chassídico. São Paulo: É Realizações, 2011. $64 \mathrm{p}$.

CAMPELLO, Tereza et al. Faces da desigualdade no Brasil: um olhar sobre os que ficam para trás. Saúde Debate, Rio de Janeiro, v. 42, n. 3, p. 54-66, nov. 2018. Disponível em: <http://www.scielo.br/scielo. php?script=sci_arttext\&pid=S0103-11042018000700054\&lng=en\&nrm=iso.> Acesso em: 20 jul. 2020. http://dx.doi.org/10.1590/0103-11042018s305.

CAMPOS, Maria Malta; ROSEMBERG, Fúlvia. Critérios para um atendimento em creches que respeite os direitos fundamentais das crianças. In: BRASIL. MEC/SEF/DPE/COEDI. Critérios para um atendimento em creches que respeite os direitos fundamentais das crianças, Brasília, DF, 1995. p. 11-25.

CORSARO, William A. Sociologia da infância. Porto Alegre: Artmed, 2011. 384 p.

CRAIDY, Carmen et al. A política de educação infantil no contexto da política da infância no Brasil. In: SIMPÓSIO NACIONAL DE EDUCAÇÃO INFANTIL: CONFERÊNCIA NACIONAL DE EDUCAÇÃO PARA TODOS, 1., 1994, Brasília, DF. Anais... Brasília, DF: MEC/SEF/DPE/COEDI, 1994. p. 18-21.

CRUZ, Silvia Helena Vieira (org.). A criança fala: a escuta de crianças em pesquisas. São Paulo: Cortez, 2008. 390 p.

DELGAD0, Ana Cristina Coll; MÜLLER, Fernanda. Abordagens etnográficas nas pesquisas com crianças e suas culturas. In: REUNIÃO ANUAL DA ANPED, 28., 2005, Caxambu. Anais... Caxambu: ANPED, 2005. Disponível em: http://www.anped.org.br/sites/default/files/gt0781 int.pdf. Acesso em: 20 jul. 2020.

DIDONET, Vital. ECA e a primeira infância. Rede Nacional da Primeira Infância, Brasília, DF, 2015. Boletim online. Disponível em: http://primeirainfancia.org.br/eca-e-primeira-infancia-por-vital-didonet-educadore-assessor-legislativo-da-rede-nacional-primeira-infancia. Acesso em: 25 de abr. 2020.

FARIA, Ana Lucia Goulart. A contribuição dos parques infantis de Mário de Andrade para a construção de uma pedagogia da educação infantil. Educação \& Sociedade, Campinas, v. 20, n. 69, p. 60-91, dez. 1999.

FERNANDES, Florestan. A constituição inacabada. São Paulo: Liberdade, 1989. 384 p.

GOBBI, Marcia Aparecida. Entre a casa, a rua e a escola: 0 que o menino viu? Itinerários de uma criança em São Paulo. Teias, Rio de janeiro, v. 19, p. 08-27, 2018.

GUIMARÃES, Daniela. Ética e cuidado, cultura e humanização: eixos do trabalho com as crianças pequenas na Educação Infantil. In: SEMINÁRIO DO PROINFANTIL, 2010, Curitiba. Anais... Curitiba: UFPR, 2010. p. 1-11. Mimeo.

GUIMARÃES, Daniela. Relações entre bebês e adultos na creche: 0 cuidado como ética. São Paulo: Cortez, 2011. $216 p$. 
KRAMER, Sonia. A política do pré-escolar no Brasil: a arte do disfarce. Rio de Janeiro: Achiamé, 1982. $144 \mathrm{p}$.

KRAMER, Sonia. Currículo de educação infantil e a formação dos profissionais de creche e pré-escola: questões teóricas e polêmicas. In: BRASIL. MEC/SEF/COEDI. Por uma política de formação do profissional de educação infantil. Brasília, DF. MEC: SEF: COEDI, 1994. p. 16-31.

KRAMER, Sonia. Direitos da criança e projeto político-pedagógico de educação infantil. In: BAZÍLIO, Luiz Cavalieri; KRAMER, Sonia (org.). Infância, educação e direitos humanos. São Paulo: Cortez, 2003. p. 59-92. 152 p.

MARCHI, Rita de Cássia; SARMENTO, Manuel Jacinto. Infância, normatividade e direitos das crianças: transições contemporâneas. Educação \& Sociedade, Campinas, v. 38, n. 141, p. 951-964, out./dez. 2017.

MONTENEGRO, Thereza. 0 cuidado e a formação moral na educação infantil. São Paulo: EDUC, 2001.

NUNES, Maria Fernanda Rezende; CORSINO, Patricia. Leitura e escrita na educação infantil: contextos e práticas em diálogo. Cadernos de Pesquisa, São Paulo, v. 49, n. 174, p. 100-129, 2019.

PENA, Alexandra. Toda vida atual é encontro: contribuições de Martin Buber para a educação. Revista Educação, Porto Alegre, v. 42, p. 506-513, 2019.

ROCHA, Eloisa Candal. A pesquisa em educação infantil no Brasil: trajetória recente e perspectivas de consolidação de uma pedagogia. Florianópolis: UFSC/CED/NUP, 1999.

ROSEMBERG, Fúlvia (org.). Creche. São Paulo: Cortez: Fundação Carlos Chagas, 1989. 252 p.

ROSEMBERG, Fúlvia. Organizações multilaterais, estado e políticas de educação infantil. Cadernos de Pesquisa, São Paulo, n. 15, p. 25-63, 2002.

ROSEMBERG, Fúlvia. Qualidade na educação infantil: uma perspectiva internacional. In: SIMPÓSIO NACIONAL DE EDUCAÇÃO INFANTIL: CONFERÊNCIA NACIONAL PARA TODOS, 1994, Brasília, DF. Anais... Brasilia, DF: MEC/SEF/DPE/COEDI, 1994. p. 154-156.

ROSEMBERG, Fúlvia; MARIANO, Carmen Lúcia Sussel. A convenção internacional sobre os direitos da criança: debates e tensões. Cadernos de Pesquisa, São Paulo, v. 40, n. 141, p. 693-728, dez. 2010.

ROSSETTI-FERREIRA, Maria Clotilde. A pesquisa na universidade e a educação da criança pequena. Cadernos de Pesquisa, São Paulo, n. 67, p. 59-63, 1988.

SARMENTO, Manuel Jacinto; GOUVEA, Maria Cristina Soares (org.). Estudos da infância: educação e práticas sociais. Petrópolis, Vozes, 2008. 280 p.

TIRIBA, Léa. Educar e cuidar: buscando a teoria para compreender os discursos e as práticas. In: KRAMER, Sonia (org.). Profissionais de educação infantil: gestão e formação. São Paulo: Ática, 2005. p. 66-97. $256 \mathrm{p}$. 
UNICEF. Fundo das Nações Unidas para a Infância. 30 anos da Convenção sobre os Direitos da Criança: avanços e desafios para meninas e meninos no Brasil. São Paulo: Unicef, 2019.

Recebido em: 26.04.2020 Revisado em: 04.06.2020 Aprovado em: 30.06.2020

Sonia Kramer é doutora em educação pela Pontifícia Universidade Católica do Rio de Janeiro (PUC-Rio). É professora da PUC-Rio, onde coordena o curso de especialização em Educação infantil, o Grupo de Pesquisa sobre Infância, Formação e Cultura (INFOC), o curso trajetórias judaicas convênio PUC-Rio e Museu de Arte do Rio (MAR); 0 Grupo Viver com Yiddish e 0 Projeto Yiddish como resistência e experiência identitária.

Maria Fernanda Rezende Nunes é professora titular-livre em educação infantil do Departamento de Didática da Universidade Federal do Estado do Rio de Janeiro (UNIRIO). É professora do Programa de Pós-Graduação em Educação da Universidade Federal do Estado do Rio de Janeiro (UNIRIO). Coordena 0 grupo de pesquisa Educação Infantil e Políticas Públicas (EIPP).

Alexandra Pena é pós-doutora em educação pela PUC-Rio. Professora do Departamento de Educação da PUC-Rio, onde coordena o curso de especialização em Educação infantil, o Grupo de Pesquisa sobre Infância, Formaç̧ão e Cultura (INFOC) e o curso de extensão em creche. 